\title{
Associations among Trauma, Posttraumatic Stress, and Hazardous Drinking in College Students: Considerations for Intervention
}

\author{
Jennifer P. Read • Sharon Radomski • Brian Borsari
}

Published online: 3 February 2015

(C) Springer International Publishing AG 2015

\begin{abstract}
Students with trauma and posttraumatic stress are disproportionately at risk for heavy drinking and for alcohol-related consequences. Brief motivational interventions (BMIs) have been shown to reduce hazardous drinking in college students, and could serve as a firstline approach to reduce heavy drinking in students with trauma and posttraumatic stress (PTS). Yet the standard BMI format may not adequately address the factors that lead to hazardous drinking in these students. Here, we review the literature on PTS and hazardous drinking in college students, and highlight cognitive (self-efficacy, alcohol expectancies) and behavioral (coping strategies, emotion regulation skills, protective behaviors) factors that may link trauma and PTS to drinking risk. Incorporating these factors into standard BMIs in a collaborative way that enhances their personal relevance may enhance intervention efficacy and acceptability for these at-risk students.
\end{abstract}

Keywords Posttraumatic stress disorder · College students . Alcohol $\cdot$ Treatment $\cdot$ Brief motivational intervention

This article is part of the Topical Collection on Alcohol

J. P. Read $(\bowtie) \cdot$ S. Radomski

Department of Psychology, University at Buffalo, State University of

New York, Buffalo, NY 15260, USA

e-mail: jpread@buffalo.edu

B. Borsari

Mental Health and Behavioral Sciences Service, Providence VAMC and Warren Alpert Medical School of Brown University, Providence, RI, USA

B. Borsari

Center for Alcohol and Addiction Studies, Brown University, Box

G-S121-5, Providence, RI 02903, USA

\section{Overview}

College students report rates of trauma and posttraumatic stress (PTS) comparable to those in community samples [1-4]. Heavy drinking and associated consequences are widespread among college students [5-7]. Recent research indicates that students with trauma and, in particular, with PTS are at elevated risk for such problematic drinking patterns $[8 \cdot, 9]$. This is true not only for students with a diagnosable posttraumatic stress disorder, but for those experiencing sub-threshold clinical PTS symptoms as well. Interventions to reduce the hazardous drinking that disproportionately affects students with PTS are needed. Brief motivational interventions (BMIs) have strong empirical support for successfully reducing problem drinking in college students $[10,11]$ and thus may offer promise in targeting drinking risk in students with PTS. Typically, BMIs administered in the college context consist of one to two individual meetings that are approximately $50 \mathrm{~min}$ long [10]. These interventions use motivational interviewing as the counseling approach, and often include personalized feedback to promote less risky drinking.

Yet, this standard BMI content may not adequately address some of the unique factors that contribute to hazardous drinking in students with trauma and posttraumatic stress. Recent work [12•] has successfully used brief intervention to reduce problem drinking in veterans with posttraumatic stress by targeting factors that may be most relevant to their experiences and symptoms. Similar approaches may be beneficial in college settings. In this article, we review the association between trauma and posttraumatic stress and alcohol involvement in college students. We then suggest several promising, theoretically based modifications that might be incorporated into BMIs designed to reduce risk drinking in this high-risk population. 


\section{Alcohol Use and Misuse in College Students}

Heavy drinking and its consequences are a widespread and well-known problem on college campuses [5, 6]. Such drinking can lead acutely to a number of significant and deleterious outcomes, including sexually transmitted diseases, vehicular accidents, and even death $[5,7,13]$. Further, those students whose drinking patterns persist are at risk for greater alcohol problems later in adulthood [14]. Not all college students are equally likely to engage in heavy drinking or to experience harmful alcohol consequences. A growing literature indicates that trauma exposure and associated posttraumatic stress are among the factors that may portend risk for problematic alcohol consumption in college students.

\section{Trauma and Posttraumatic Stress in College Students}

Approximately two out of three college students report trauma exposure [1,2], a percentage consistent with rates reported in the general community [15]. The types of traumas that students report are significant by any standard. Sexual victimization is particularly common in this population $[16,17]$, but other types of traumatic events typically reported include the sudden death of a loved one, non-sexual assault, natural disasters, and motor vehicle accidents [2, 18-20]. High rates of combat trauma and alcohol use have been reported in student service members/veterans pursuing higher education under the GI-bill [21]. For some, trauma exposure can lead to symptoms of posttraumatic stress disorder (PTSD), a disorder characterized by traumatic intrusions, avoidance of trauma stimuli, alterations in mood and cognition, and hyper-arousal/reactivity $[22,23]$. These symptoms are best understood as occurring along a spectrum of severity, rather than as a categorical symptom state [24-28]. As such, even symptom presentations that fall below conventional diagnostic cutoffs may be associated with significant distress and functional impairment [8•, 29-32]. Consistent with community prevalence rates [15], an estimated $8-9 \%$ of college students meet the diagnostic criteria for PTSD [2, 3, 33], and an even larger number (15$30 \%)$ show evidence of clinically significant but subdiagnostic threshold posttraumatic stress symptoms [2]. In the present paper, we consider this broad range of clinically significant symptoms, which we refer to as posttraumatic stress, or PTS.

\section{Posttraumatic Stress and Drinking Risk in Young Adults}

Traumatic life events and the range of stress responses to them long have been linked to problem drinking in clinical samples [34], and an emerging literature has demonstrated this link to occur in college students as well [35]. In just the past few years, data have emerged to show that college students with trauma exposure and PTS drink more and experience worse consequences than those without PTS [8•, 9, 36-38]. Importantly, the literature points to PTSD symptoms specificallyand not just having been exposed to trauma - as being most clearly associated with hazardous drinking [e.g., 8•]. Below, we review a sampling of this literature.

Concurrent Associations Studies examining concurrent relations between trauma and PTS and alcohol involvement in college samples find that trauma and PTS are associated with greater problematic drinking $[8 \cdot 38,39-42]$. Convergent with these findings are recent data that show students with PTSD place a greater value (demand) on alcohol than students without these symptoms, suggesting that alcohol may be especially salient and appealing to those struggling with PTSD [43]. Work conducted in our own lab also demonstrates significant risk for problem drinking among students with PTS [Radomski and Read, manuscript under review]. Specifically, those categorized through a structured diagnostic interview as having clinically significant PTS $(N=113 ; M=6.58)$ report approximately $25 \%$ more alcohol problems over the 30 days than those with trauma exposure but no PTS $(N=172 ; M=$ 9.22 ), and $50 \%$ more than those with no trauma exposure at all $(N=182 ; M=14.38)$.

Prospective Associations Prospective investigations of trauma, PTS, and drinking in college samples have been far fewer. Our recent study [8•] found that students who entered college with clinically significant posttraumatic stress went on to experience substantially more alcohol consequences than those without these symptoms over the course of that first college year. A small number of other longitudinal studies also offer evidence of a prospective influence of PTS on drinking in both the short [42] and the longer-term [45]. Yet, these and other studies suggest that the patterns of influence of PTSD on drinking are complex and may also be bidirectional; with one influencing the other over time [e.g., 41, 44•, 45]. Especially troubling are studies showing that for those with trauma and PTS, heavy drinking can lead directly to increased risk for trauma re-exposure [46] and perhaps also for a spiral of worsening PTS symptoms [47].

Considered in aggregate, the literature suggests that efforts to acutely address and reduce hazardous drinking in students with significant PTS clearly are needed. Interventions have been developed for PTS and problem drinking as they occur both independently and together [48-51]. The majority of these interventions are cognitive-behaviorally oriented, and focus on maladaptive cognitions and behavioral skills deficits that are presumed to contribute to symptom presentation. Typically, these multi-session interventions call for a substantial time commitment, and many require professional facilitation. Moreover, CBT-based interventions for PTS frequently are 
exposure-based. None of these characteristics is practical for routine implementation in the college setting. Yet from these interventions and their emphasis on critical cognitions and behaviors, valuable insight can be derived regarding what components may be incorporated into a less intensive intervention approach, such as a brief motivational intervention.।

\section{Reducing Alcohol Misuse in College Students with Posttraumatic Stress: Implications for Brief Motivational Interventions}

Brief motivational interventions (BMI) have shown efficacy in reducing alcohol misuse in college populations, and already are being used on many US campuses [52-55]. These interventions incorporate features of motivational interviewing [MI; 56], into a focused, time-limited intervention to target behavior change. Work in the late 1990s and early 2000s first documented the efficacy of BMIs, showing significant reductions in alcohol use and consequences as far out as 4 years [57, 58]. Since then, this approach has been implemented successfully across numerous populations, modalities, and settings [59-62]. Motivational interviewing fosters a collaborative, empathic, and non-judgmental approach to the exploration of options for change. In addition, there are specific techniques to prevent discord in the therapeutic relationship (e.g., emphasizing personal choice and control, eliciting personal motivations for change; [56, 63]). Thus, MI is well suited to a population that may be new to treatment and in considerable distress. Further, the one to two session format of BMI may be ideal for college students - a group typically reticent to engage in more formal and extensive treatment $[64,65]$.

The evidence for the efficacy of traditional, stand-alone BMIs to reduce problem drinking in persons with cooccurring mood/anxiety symptoms has been somewhat mixed [59, 66-72]. However, recent work implementing BMIs with veterans highlights the potential for such interventions to reduce harmful alcohol use in individuals with PTS [12•, 73•]. It also is interesting to note that in these studies, the BMI modified to target PTS-relevant factors not only yielded drinking reductions, but PTS reductions as well. Based on this, we assert that BMI may be a promising approach that could be used in the service of decreasing heavy drinking - and perhaps also PTSD symptoms - in students with PTS.

To date, only a few studies have implemented BMIs for college students with trauma histories and only one of these [76•] has focused on students with posttraumatic stress and not only trauma exposure. Though small, this body of research does suggest that BMIs can result in improved drinking outcomes for college students. For example, Clinton-Sherrod et al. [74] examined differences in variations of a standard BMI (BMI only, BMI with feedback, feedback only) and an assessment control among women with and without sexual trauma. Posttraumatic stress was not assessed. In this study, the BMI was associated with drinking reductions in both victimized and non-victimized women. However, findings revealed some differences across victimization groups in how this change occurred, as there was evidence of weaker effects of the feedback-only component of the intervention for women with sexual trauma. This suggested that there was something important about the motivational intervention itself for sexually victimized women. In considering the findings, these authors called for greater attention to specific components of BMI to better understand how these components may interact with trauma history. In a subsequent study, Brahms et al. [75] also found that a standard BMI appeared to result in short-term drinking reductions in women with sexual trauma (again, PTS was not examined). Similarly, authors suggested a need for increased focus on specific, trauma-relevant components of the intervention as in this study women with trauma histories did not show improvements in positive coping that were observed in women without sexual trauma.

To our knowledge, only one study to date has examined the impact of posttraumatic stress specifically on drinking outcomes following BMI. In their study, Monahan et al. [76•] compared an in-person standard BMI, a computerized standard BMI, and an assessment-only condition in students with and without PTS. Encouragingly, decreases in drinking were observed in students with PTS, though the overall effect sizes of drinking reductions were smaller (d's .13-.14) than what is typically observed in BMI interventions. Findings also showed that reductions in alcohol consequences occurred only for the PTS students who received an in-person BMI. In addition, for those who received assessment only, there was a trend for students with PTS to show worse drinking outcomes over time relative to the MI conditions. When considering their findings, the authors speculated that the success of the counselor-based intervention may have been due in part to the fact that within this format, the link between PTS and drinking could be explicitly addressed.

In sum, a nascent literature offers support for the application of brief motivational interventions to reduce drinking in those with trauma and PTS. However, these studies also highlight the potential utility of tailoring interventions to address some of the factors that may be especially important to students with these histories and clinical presentations. Fortunately, there is strong precedence for the adaptation of BMIs to enhance their efficacy or to make them more appropriate for specific populations [66, 77-79]. This research indicates that BMIs can be modified effectively to include populationrelevant topics or components, without losing the essential features thought to be integral to their success. Further, in many cases, modified interventions show stronger effects on drinking outcomes than are typically seen in standard, unmodified BMIs (see $[66,80]$ for reviews). Therefore, it may be 
practical to consider theoretically based modifications to standard BMIs that might enhance efficacy by making them more relevant and meaningful for students with trauma and posttraumatic stress.

\section{Theorized Mechanisms for a Modified BMI}

Two related and complementary theories suggest promising modifications to BMIs for students with co-morbid PTS and alcohol misuse. First, Social Learning Theory (SLT; [81]) emphasizes drinking as a learned behavior with affective as well as cognitive and behavioral antecedents. Second, Hobfoll's Conservation of Resources (CoR) theory [82] conceptualizes post-trauma adaptation as occurring through either a gain or loss of psychological resources. In cases where trauma leads to loss of these resources, the individual is rendered more vulnerable to additional loss and harmful outcomes (e.g., alcohol misuse). These theories, when taken in the context of the larger literature on effective treatments for PTS and problem drinking, offer several promising cognitive (self-efficacy, expectancies) and behavioral (coping, emotional regulation, protective behaviors) foci which we believe are important to address in a BMI for college students with PTS and alcohol misuse (see Table 1). We review each of these critical concepts, their theoretical underpinnings, and their potential relevance to a college-based BMI.

\section{Cognitions}

Self-efficacy Self-efficacy refers to the extent to which someone believes she/he is capable of successfully managing a challenging circumstance [83]. The self-efficacy construct is featured prominently in SLT as a mediating cognitive mechanism that links more distal psychosocial influences to alcohol outcomes. When applied to the link between traumatic stress symptoms and drinking, the extent to which someone believes herself/himself capable of managing trauma-related distress without alcohol likely will be an important determinant of drinking outcomes. Hobfoll also incorporates self-efficacy in his CoR theory, conceptualizing this characteristic as a personal resource that may be compromised in the wake of trauma. The empirical literature supports this theorized pathway, as trauma-exposed individuals show evidence of diminished self-efficacy across multiple domains, including substance use $[40,84,85]$. In our own lab, we have found that trauma and PTS may be uniquely associated with drinking-related selfefficacy [Read et al., unpublished data]. Specifically, using the Tension Reduction subscale from the Situational Confidence Questionnaire [86], we find that students with PTS report significantly lower self-efficacy for not drinking when they are in a negative mood, relative to those without trauma or to those reporting trauma but without clinically significant PTSD symptoms. This pattern of findings suggests that students with PTS may be more vulnerable to using alcohol due to diminished self-efficacy. Self-efficacy already is targeted in the standard BMI format (supporting self-efficacy for behavior change is a core principle of MI). Yet, in light of both theory and data described here, a modified BMI for PTS may benefit by focusing on the specific connection between trauma/PTS and self-efficacy, possibly focusing on enhancing a sense of control and mastery that may have been diminished by trauma and its effects.

Expectancies These learned beliefs about alcohol's effects are posited in SLT to be a mechanistic pathway to problem drinking $[87,88]$. Alcohol expectancy information addressed in standard BMI approaches has been linked to short-term reductions in alcohol use in college students without trauma [52]. However, expectancies which pertain to the amelioration of negative affect may be of particular relevance for understanding PTS and drinking. Indeed, expectancies are an important predictor of drinking among those with PTS [40] and expectancies pertaining to alcohol's ability to moderate or alleviate negative affect (e.g., tension reduction expectancies) are commonly held by those with trauma and posttraumatic stress [89, 90]. Moreover, specific expectations regarding the use of alcohol to relieve PTSD symptoms have been identified in PTS individuals [91, 92]. Accordingly, a focus on both tension reduction and PTSD-specific expectancies may be of benefit to a BMI for students with trauma and PTS as it would highlight affect regulation and affect management skills (e.g., urge surfing, relaxation/grounding, social skills) that may be useful for those who may otherwise look to drinking for symptom reduction.

\section{Behaviors}

Coping Coping has been identified as an important mechanistic variable in associations between posttraumatic stress and drinking [44, 93]. Coping also is a core component of many cognitive-behaviorally based interventions for PTS and for substance misuse, as the extent to which someone can manage distress may determine behavioral outcomes such as posttraumatic stress symptoms or substance misuse $[118,94]$. The CoR model asserts that the experience of trauma and resulting posttraumatic stress may tax cognitive and emotional resources, leaving the individual less able to manage distress $[82,95]$. Therefore, those with PTS may lack adequate coping skills, instead using alcohol to cope with their symptoms [96]. Consistent with this conceptualization are data showing that those with PTS show poorer coping relative to those without PTS [97]. In a college sample, Grasson [98] found that students with PTS reported significantly greater use of 


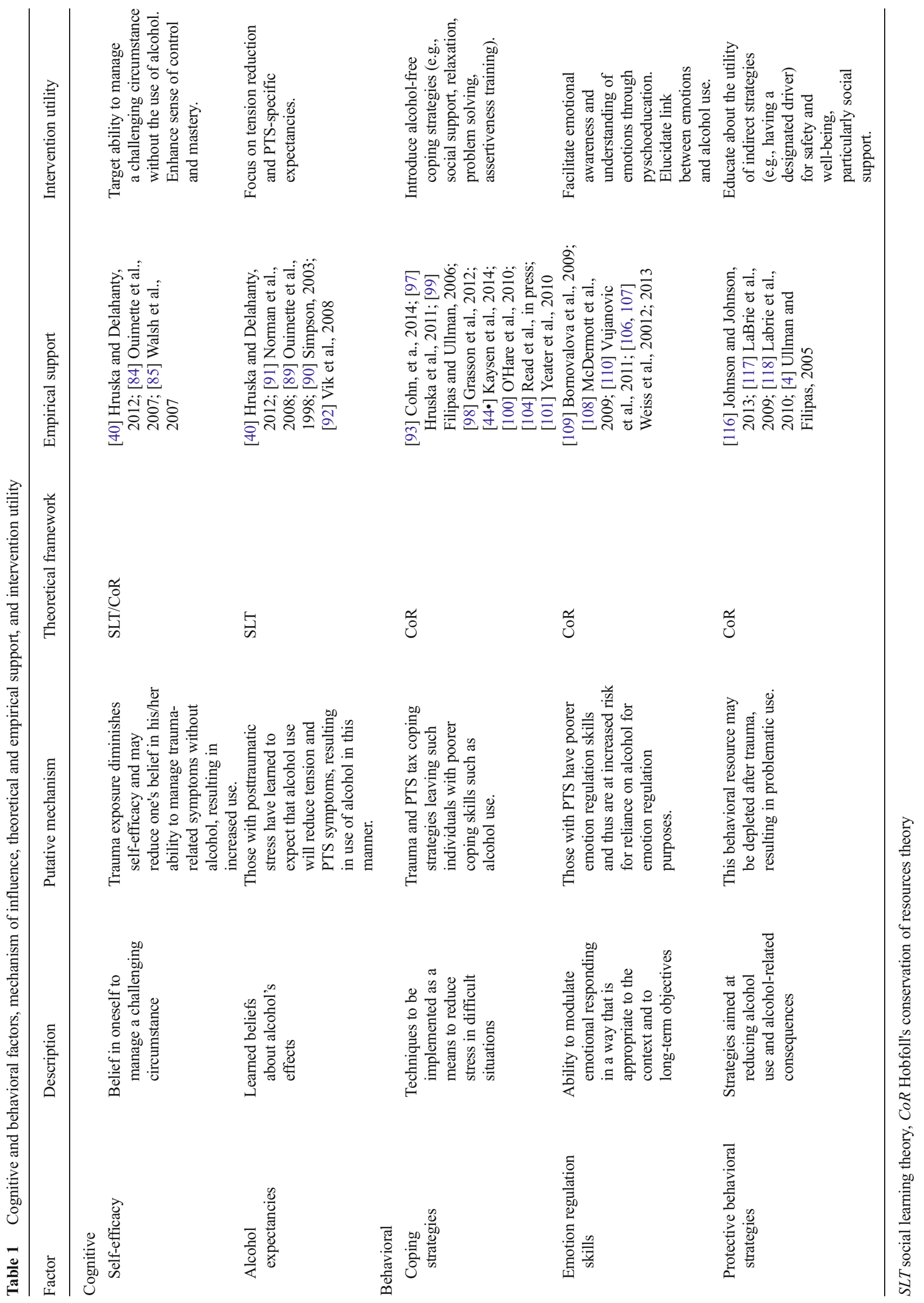


maladaptive coping strategies (e.g., denial, substance use, self-blame) than students without PTS, regardless of trauma history. In another college sample, Read et al. found posttraumatic stress to be prospectively related to poorer coping over time [104]. Although coping did not mediate PTS-alcohol associations in this study, several other studies have found at least partial support for a meditational role of coping [99-101]. In addition to coping skills themselves, the motivation to drink in order to cope - specifically with PTS - may also be an important factor to consider $[9,102,103]$. Though not part of the standard BMI format, because of its significance for PTS-drinking, coping has been incorporated in recent BMIs designed to reduce drinking in veterans with posttraumatic stress [12•, 104]. Therefore, college students with PTS may benefit from a component incorporated in a modified BMI focusing on coping without drinking. The incorporation of a coping component into BMI may also have diagnostic value, as a focused discussion about coping could help to identify whether the student is lacking alcohol-free coping strategies, lack motivation to implement them, or a combination of both.

Emotion Regulation Skills Emotion regulation (ER) refers to the ability to modulate emotional responding in a way that is appropriate to the context and to long-term objectives [105]. Emotion regulation is another personal resource that may be compromised following trauma, consistent with a CoR framework. Indeed, poor emotion regulation confers vulnerability for substance misuse, as those who cannot successfully manage negative emotions such as PTS symptoms may instead turn to substances. Emotion regulation deficits have been observed in those with trauma and posttraumatic stress who misuse substances [106, 107], and to reliably distinguish between substance-dependent individuals with and without PTS [108]. Research in non-college samples has offered support for a mechanistic role of emotion regulation in PTS-alcohol associations $[109,110]$. Importantly, recent work with college students (Radomski and Read, under review) indicates that those with PTSD reported more difficulty in emotion regulation than those without trauma exposure and those with trauma exposure but without PTS. Moreover, difficulty in emotion regulation mediated the PTSD-alcohol association. Although focus on emotion regulation is not addressed in the standard college drinking BMI, ER has been integrated into other brief interventions with other populations [e.g., 111]. As a component of ER pertains to awareness and understanding of emotions [112], facilitating emotional awareness and the link between emotions and drinking, as well as on broader ER strategies may be a valuable addition to BMIs for college students with PTS.

Protective Behaviors Protective behaviors are any behavioral efforts to reduce heavy drinking and its associated consequences [113-115]. These behaviors typically include approaches such as pacing drinking, avoiding high-risk drinking activities (e.g., drinking games), or pairing with a friend to protect against hazardous outcomes (e.g., assault, criminal victimization) and are consistent with the kinds of skills typically taught in CBT interventions for PTS and problem drinking. Yet though these behaviors have the potential to buffer against harmful drinking outcomes [116], some evidence suggests that these behaviors may be less effectively implemented in those with mental health problems $[117,118]$ and as such, this may be an important focus of intervention for these individuals. In particular, "indirect" protective behaviors that involve using others as a resource may be especially important for those with trauma and PTS, as the literature has pointed to the centrality of strong social support in post-trauma adaptation [119]. This literature also suggests that, consistent with a CoR conceptualization, those with PTS may have difficulty effectively employing social support resources in the wake of trauma [120]. Protective behaviors routinely are targeted in $\mathrm{BMI}$, and could be readily modified to include a specific focus on effective utilization of social support (e.g., having a safe "buddy" to drink with). This may not only reduce drinking risk, but may also reduce risk for additional trauma exposure.

\section{Conclusion}

Students with trauma and posttraumatic stress drink more hazardously, encounter more significant consequences from their drinking, and are at risk for a number of other deleterious outcomes relative to students without these experiences and symptoms. This risk is evident across a range of posttraumatic stress symptom severity, not just diagnosable PTSD, and also pertains to both immediate and longer-term outcomes. In this paper, we have highlighted some of the important vulnerabilities that may contribute to drinking risk in students with PTS. These include maladaptive coping, lower self-efficacy for refusing alcohol when in a negative mood state, poorer emotion regulation, less engagement in protective behaviors, and greater expectations for alcohol's self-medicating effects. Effective interventions are needed for this group of students. Alcoholfocused BMIs already are being delivered on many US college campuses and a small but growing literature has demonstrated that BMIs can be used to reduce heavy drinking and its consequences in college students with trauma histories [74, 75] and associated posttraumatic stress [76 ]. We posit that there is much more that can be done to target cognitive and behavioral factors most relevant to these individuals. Further, the modifications proposed here could be the first step in more elaborated interventions for heavy drinking students with PTS. For example, the modified BMI could also be further adapted to enhance treatment motivation in heavy drinking 
students, with the hope that such intervention would facilitate engagement in more intensive treatments (e.g., Seeking Safety). Alternatively, a modified BMI could be offered as a complement to a standard PTS intervention (e.g., prolonged exposure, anxiety management, cognitive restructuring) so that alcohol risk could be diminished acutely even as more focused treatment for PTS continues. Finally, detailed analysis of insession therapist and client behaviors and their link to subsequent outcomes $[121,122]$ will further enhance our understanding of how BMIs can facilitate change in a variety of target behaviors (alcohol use and consequences, protective behavioral strategies, treatment engagement). This kind of systematic and thoughtful evaluation will provide an improved understanding of which BMI components and insession processes contribute to the reduction of problem drinking and perhaps also PTS. This ultimately will lead to knowledge about how brief interventions might be augmented to be optimally beneficial to and relevant for the many college students struggling with trauma and its negative effects.

\begin{abstract}
Acknowledgments Jennifer Read's contribution to this manuscript was supported by the National Institute on Alcohol Abuse and Alcoholism Grant R01AA016564. Brian Borsari's contribution to this manuscript was supported by the National Institute on Alcohol Abuse and Alcoholism Grant R01-AA017427 and VISN1 Career Development Award V1CDA2012-18. The contents of this manuscript are those of the authors and do not necessarily represent the views of the National Institute on Alcohol Abuse and Alcoholism, the Department of Veterans Affairs, or the US Government.
\end{abstract}

\section{Compliance with Ethics Guidelines}

Conflict of Interest Jennifer P. Read declares that she has no conflict of interest.

Sharon Radomski declares that she has no conflict of interest.

Brian Borsari declares that he has no conflict of interest.

Human and Animal Rights and Informed Consent This article does not contain any studies with human or animal subjects performed by any of the authors.

\section{References}

Papers of particular interest, published recently, have been highlighted as:

- Of importance

1. Marx BP, Sloan DM. The effects of trauma history, gender, and race on alcohol use and posttraumatic stress symptoms in a college student sample. Addict Behav. 2003;28(9):1631-47.

2. Read JP, Ouimette P, White J, Colder C, Farrow S. Rates of DSM IV-TR trauma exposure and posttraumatic stress disorder among newly matriculated college students. Rates of DSM IV-TR trauma exposure and posttraumatic stress disorder among newly matriculated college students. Psychol Trauma: Theory Res Pract Policy. 2011;3:148-56.

3. Smyth JM, Hockemeyer JR, Heron KE, Wonderlich SA, Pennebaker JW. Prevalence, type, disclosure, and severity of adverse life events in college students. J Am Coll Heal. 2008;57(1): 69-76.

4. Ullman SE, Filipas HH. Ethnicity and child sexual abuse experiences of female college students. J Child Sex Abus. 2005;14(3): 67-89.

5. Hingson RW. Magnitude and prevention of college drinking and related problems. Alcohol Res Health. 2010;33:45-54.

6. Johnston LD, O'Malley PM, Bachman JG, Schulenberg JE. Monitoring the future national survey results on drug use, 19752006: volume II, college students and adults ages 19-45 (NIH Publication no. 07-6206). Bethesda: National Institute on Drug Abuse; 2007.

7. Perkins H. Surveying the damage: a review of research on consequences of alcohol misuse in college populations. J Stud Alcohol Drugs. 2002;14:91-100.

8. Read JP, Colder CR, Merrill JE, Ouimette P, White J, Swartout A. Trauma and posttraumatic stress symptoms influence alcohol and other drug problem trajectories in the first year of college. J Consult Clin Psychol. 2012;80:426-39. This is on of the earliest examinations of longer-term prospective associations between PTSD and alcohol outcomes in college students.

9. Stappenbeck CA, Bedard-Gilligan M, Lee CM, Kaysen D. Drinking motives for self and others predict alcohol use and consequences among college women: the moderating effects of PTSD. Addict Behav. 2013;38(3):1831-9.

10. Carey KB, Henson JM, Carey MP, Maisto SA. Which heavy drinking college students benefit from a brief motivational intervention? J Consult Clin Psychol. 2007;75:663-9.

11. Cronce JM, Larimer ME. Individual-focused approaches to the prevention of college student drinking. Alcohol Res Curr Rev. 2011;34(2):210-21.

12. Brief DJ, Rubin A, Keane TM, Enggaser JL, Roy M, Helmuth E, et al. Web intervention for OEF/OIF veterans with problem drinking and PTSD symptoms: a randomized clinical trial. J Consult Clin Psychol. 2013;82:890-900. This is the first study to our knowledge to examine the use of brief intervention to intervene on drinking behaviors in those with posttraumatic stress.

13. Hingson RW, Zha W. Age of drinking onset, alcohol use disorders, frequent heavy drinking, and unintentionally injuring oneself and others after drinking. Pediatrics. 2009;123(6):1477-84.

14. Jackson KM, Sher KJ, Gotham HJ, Wood PK. Transitioning into and out of large-effect drinking in young adulthood. J Abnorm Psychol. 2001;110(3):378-91.

15. Breslau N, Kessler RC, Chilcoat HD, Schultz LR, Davis GC, Andreski P. Trauma and posttraumatic stress disorder in the community: the 1996 Detroit area survey of trauma. Arch Gen Psychiatry. 1998;55:626-32.

16. Abbey A. Alcohol-related sexual assault: a common problem among college students. J Stud Alcohol. 2002;14(Suppl):118-28.

17. Testa M, Hoffman JH, Livingston JA. Alcohol and sexual risk behaviors as mediators of the sexual victimization-revictimization relationship. J Consult Clin Psychol. 2010;78(2):249-59.

18. Bernat JA, Ronfeldt HM, Calhoun KS, Arias I. Prevalence of traumatic events and peritraumatic predictors of posttraumatic stress symptoms in a nonclinical sample of college students. J Trauma Stress. 1998;11:645-64.

19. Fisher BS, Cullen FT, Turner MG. The sexual victimization of college women. Washington: US Department of Justice, National Institute of Justice and Bureau of Justice Statistics; 2000.

20. Smith-Osbourne A. Mental health risk and social ecological variables associated with educational attainment for Gulf War 
veterans: implications for veterans returning to civilian life. Am J Community Psychol. 2009;44:327-37.

21. Barry AE, Whiteman SD, MacDermid Wadsworth S. Student service members/veterans in higher education: a systematic review. J Stud Aff Res Pract. 2014;51(1):30-42.

22. American Psychiatric Association. Diagnostic and statistical manual of mental disorders IV-TR (Text Revision). Washington: Author; 2000.

23. American Psychiatric Association. Diagnostic and statistical manual of mental disorders. 5th ed. Washington: Author; 2013.

24. Berna G, Vaiva G, Ducrocq F, Duhem S, Nandrino JL. Categorical and dimensional study of the predictive factors of the development of a psychotrauma in victims of car accidents. J Anxiety Disord. 2012;26(1):239-45.

25. Breslau N, Reboussin BA, Anthony JC, Storr CL. The structure of posttraumatic stress disorder: latent class analysis in 2 community samples. Arch Gen Psychiatry. 2005;62(12):1343-51.

26. Broman-Fulks JJ, Ruggiero KJ, Green BA, Kilpatrick DG, Danielson CK, Resnick HS, et al. Taxometric investigation of PTSD: data from two nationally representative samples. Behav Ther. 2006;37(4):364-80.

27. Brown TA, Barlow DH. Dimensional versus categorical classification of mental disorders in the fifth edition of the Diagnostic and Statistical Manual of Mental Disorders and beyond: comment on the special section. J Abnorm Psychol. 2005;114(4):551-6.

28. Mulder R, Fergusson D, Horwood J. Posttraumatic stress disorder symptoms form a traumatic and non-traumatic stress response dimension. Aust N Z J Psychiatry. 2013;47(6):569-77.

29. Pietrzak RH, Goldstein RB, Southwich SM, Grant BF. Medical comorbidity of full and partial posttraumatic stress disorder in US adults: results from wave 2 of the National Epidemiologic Survey on Alcohol and Related Conditions. Psychosom Med. 2011;73: 697-707.

30. Schnurr PP, Ford JD, Friedman MJ, Green BL, Dain BJ, Sengupta A. Predictors and outcomes of posttraumatic stress disorder in World War II veterans exposed to mustard gas. J Consult Clin Psychol. 2000;68:258-68.

31. Stein MB, Walker JR, Hazen AL, Forde DR. Full and partial posttraumatic stress disorder: findings from a community survey. Am J Psychiatr. 1997;154:1114-9.

32. Zlotnick C, Franklin CL, Zimmerman M. Does "subthreshold" posttraumatic stress disorder have any clinical relevance? Compr Psychiatry. 2002;43:413-9.

33. McDevitt-Murphy ME, Weathers FW, Flood AM, Eakin DE, Benson TA. The utility of the PAI and the MMPI-2 for discriminating PTSD, depression, and social phobia in trauma-exposed college students. Assessment. 2007;14(2):181-95.

34. Bailey KM, Stewart SH. Relations among trauma, PTSD, and substance misuse: the scope of the problem. In: Ouimette P, Read JP, editors. Trauma and substance abuse: causes, consequences, and treatment of comorbid disorders. 2nd ed. Washington: American Psychological Association; 2013.

35. Borsari B, Read JP, Campbell JF. Posttraumatic stress disorder and substance use disorders in college students. J Coll Stud Psychother. 2008;22:61-85.

36. Barry AE, Whiteman SD, MacDermid Wadsworth SM. Implications of posttraumatic stress among military-affiliated and civilian students. J Am Coll Heal. 2012;60(8):562-73.

37. Miron LR, Orcutt HK, Hannan SM, Thompson KL. Childhood abuse and problematic alcohol use in college females: the role of self-compassion. Self Identity. 2014;13(3):364-79.

38. Walsh K, Resnick HS, Danielson CK, McCauley JL, Saunders BE, Kilpatrick DG. Patterns of drug and alcohol use associated with lifetime sexual revictimization and current posttraumatic stress disorder among three national samples of adolescent, college, and household-residing women. Addict Behav. 2014;39(3):684-9.

39. Dvorak RD, Arens AM, Kuvaas NJ, Williams TJ, Kilwein TM. Problematic alcohol use, trauma history, and PTSD symptom level: a path analysis. J Dual Diagn. 2013;9(4):281-91.

40. Hruska B, Delahanty DL. Application of the stressor-vulnerability model to understanding posttraumatic stress disorder (PTSD) and alcohol related problems in an undergraduate population. Psychol Addict Behav. 2012;26:734-46.

41. Read JP, Merrill JE, Griffin MJ, Bachrach RL, Khan SN. Posttraumatic stress symptoms and alcohol problems: self-medication or trait vulnerability? Am J Addict. 2014;23(2):108-16.

42. Simpson TL, Stappenbeck CA, Luterek JA, Lehavot K, Kaysen DL. Drinking motives moderate daily relationships between PTSD symptoms and alcohol use. J Abnorm Psychol. 2014;123(1):237.

43. Murphy JG, Yurasek AM, Dennhardt AA, Skidmore JR, McDevitt-Murphy ME, MacKillop J, et al. Symptoms of depression and PTSD are associated with elevated alcohol demand. Drug Alcohol Depend. 2013;127:129-36.

44. Kaysen D, Atkins DC, Simpson TL, Stappenbeck CA, Blayney JA, Lee CM, et al. Proximal relationships between PTSD symptoms and drinking among female college students: results from a daily monitoring study. Psychol Addict Behav. 2014;28(1):62-73. This is one of the only studies to examine daily associations between PTSD and alcohol consumption in college students.

45. Read JP, Wardell JD, Colder CR. Reciprocal associations between PTSD symptoms and alcohol involvement in college: a three-year trait-state-error analysis. J Abnorm Psychol. 2013;122(4):984-97.

46. Messman-Moore TL, Ward RM, Zerubavel N. The role of substance use and emotion dysregulation in predicting risk for incapacitated sexual revictimization in women: results of a prospective investigation. Psychol Addict Behav. 2013;27:125-32.

47. Read JP, Bachrach RL, Wright A, Colder CR. (under review). The course of PTSD symptoms in the first year of college: Symptom transitions, trauma exposure, and alcohol involvement.

48. Miller WR, Wilbourne PL, Hettema JE. What works? A summary of alcohol treatment outcome research. In: Hester RK, Miller WR, editors. Handbook of alcoholism treatment approaches: effective alternatives. 3rd ed. Boston: Allyn \& Bacon Publishers; 2003. p. $13-63$.

49. Monson CM, Shnaider P. Trauma-focused interventions: cognitive techniques and treatment packages. In: Monson CM, Shnaider P, editors. Treating PTSD with cognitive-behavioral therapies: interventions that work. Washington: US: American Psychological Association; 2014. p. 51-79.

50. Back SE. Toward an improved model of treating co-occurring PTSD and substance use disorders. Am J Psychiatr. 2010;167:11-3.

51. Najavits LM. Seeking Safety: Therapy for Posttraumatic Stress Disorder and Substance Use Disorder. In: Follette VM, Ruzek J, editors. Cognitive-behavioral therapies for trauma (2nd ed.). New York, NY, US: Guilford Press, pp.228-257.

52. Borsari B, Carey KB. Effects of a brief motivational intervention with college student drinkers. J Consult Clin Psychol. 2000;68: 728-33.

53. Borsari B, Carey KB. Two brief alcohol interventions for mandated college students. Psychol Addict Behav. 2005;19:296-302.

54. Kazemi DM, Sun L, Nies MA, Dmochowski J, Walford SM. Alcohol screening and brief interventions for college freshmen. J Psychosoc Nurs Ment Health Serv. 2011;49(1):35-42.

55. Walters ST, Vader AM, Harris TR, Field CA, Jouriles EN. Dismantling motivational interviewing and feedback for college drinkers: a randomized clinical trial. J Consult Clin Psychol. 2009;77:64-73.

56. Miller WR, Rollnick S. Motivational interviewing: helping people change. 3rd ed. New York: Guilford Press; 2012. 
57. Baer JS, Kivlahan DR, Blume AW, McKnight P, Marlatt GA. Brief intervention for heavy-drinking college students: 4-year follow-up and natural history. Am J Public Health. 2001;91:1310-6.

58. Marlatt AG, Baer JS, Kivlahan DR, Dimeff LA, Larimer ME, Quigley LA, et al. Screening and brief intervention for high-risk college student drinkers: results from a 2-year follow-up assessment. J Consult Clin Psychol. 1998;66:604-15.

59. Carey KB, Scott-Sheldon LA, Carey MP, DeMartini KS. Individual-level interventions to reduce college student drinking: a meta-analytic review. Addict Behav. 2007;32(11):2469-94.

60. Dimeff LA, Baer JS, Kivlahan DR, Marlatt GA. Brief alcohol screening and intervention for college students (BASICS): a harm reduction approach. New York: The Guilford Press; 1999.

61. Larimer ME, Cronce JM. Identification, prevention, and treatment: a review of individual-focused strategies to reduce problematic alcohol consumption by college students. J Stud Alcohol. 2002;14:148-63.

62. Larimer ME, Cronce JM. Identification, prevention, and treatment revisited: Individual-focused college drinking prevention strategies 1999-2006. Addict Behav. 2007;32:2439-68.

63. Moyers TB, Miller WR. Is low therapist empathy toxic? Psychol Addict Behav. 2013;27:878-84.

64. Eisenberg D, Hunt J, Speer N, Zivin K. Mental health service utilization among college students in the United States. J Nerv Ment Dis. 2011;199:301-8.

65. Epler AJ, Sher KJ, Loomis TB, O’Malley SS. College student receptiveness to various alcohol treatment options. J Am Coll Heal. 2009;58:26-32.

66. Baker AL, Thornton LK, Hiles S, Hides L, Dubman DI. Psychological interventions for alcohol misuse among people with co-occurring depression or anxiety disorders: a systematic review. J Affect Disord. 2012;139:217-29.

67. Feldstein Ewing SW, LaChance HA, Bryan A, Hutchison KE. Do genetic and individual risk factors moderate the efficacy of motivational enhancement therapy? Drinking outcomes with an emerging adult sample. Addict Biol. 2009;14:356-65.

68. Geisner IM, Neighbors C, Lee CM, Larimer ME. Evaluating personal alcohol feedback as a selective prevention for college students with depressed mood. Addict Behav. 2007;32:2776-87.

69. Merrill JE, Reid AE, Carey MP, Carey KB. Gender and Depression Moderate Response to Brief Motivational Intervention for Alcohol Misuse Among College Students. J Consult Clin Psychol. 2014.

70. Randall CL, Thomas S, Thevos A. Concurrent alcoholism and social anxiety disorder: a first step toward developing effective treatments. Alcohol Clin Exp Res. 2001;25:210-20.

71. Stein LAR, Clair M, Lebeau R, Colby SM, Barnett NP, Golembeske $\mathrm{C}$, et al. Motivational interviewing to reduce substance-related consequences: effects for incarcerated adolescences with depressed mood. Drug Alcohol Depend. 2011;118: 475-8.

72. Terlecki MA, Buckner JD, Larimer ME, Copeland AL. Brief motivational intervention for college drinking: the synergistic impact of social anxiety and perceived drinking norms. Psychol Addict Behav. 2012;26:917-23.

73. McDevitt-Murphy ME, Murphy JG, Williams JL, Monahan CJ, Bracken-Minor KL, Fields JA. Randomized controlled trial of two brief alcohol interventions for oef/oif veterans. J Consult Clin Psychol. 2014;82(4):562-8. This study demonstrates the efficacy brief interventions (including a motivational intervention) in successfully reducing alcohol consumption in individuals with PTSD.

74. Clinton-Sherrod M, Morgan-Lopez AA, Brown JM, McMillen BA, Cowells A. Incapacitated sexual violence involving alcohol among college women: the impact of a brief drinking intervention. Violence Against Women. 2011;17:135-54.
75. Brahms E, Ahl M, Reed E, Amaro H. Effects of an alcohol intervention on drinking among female college students with and without a recent history of sexual violence. Addict Behav. 2011;36: 1325-8.

76. Monahan CJ, McDevitt-Murphy ME, Dennhardt AA, Skidmore JR, Martens MP, Murphy JG. The impact of elevated posttraumatic stress on the efficacy of brief alcohol interventions for heavy drinking college students. Addict Behav. 2013;38:1719-25. This is the only study to date that has examined the impact of posttraumatic stress specifically on drinking outcomes in college students following BMI.

77. Lee CS, López SR, Hernández L, Colby SM, Caetano R, Borrelli $\mathrm{B}$, et al. A cultural adaptation of motivational interviewing to address heavy drinking among Hispanics. Cult Divers Ethn Minor Psychol. 2011;17:317-24.

78. Pedrelli P, Borsari B, Fava M, Daulton E, Palm K. Combined $\mathrm{BMI}+\mathrm{CBT}$ for depressive symptoms and binge drinking among young adults: Description of the theoretical background and preliminary findings. J Cogn Psychother. 2014.

79. Murphy JG, Dennhardt AA, Skidmore JR, Borsari B, Barnett NP, Colby SM, et al. A randomized controlled trial of a behavioral economic supplement to brief motivational interventions for college drinking. J Consult Clin Psychol. 2012;80:876-86.

80. Hesse M. Integrated psychological treatment for substance use and comorbid anxiety or depression vs. treatment for substance use alone. A systematic review of the published literature. BMC Psychiatry. 2009;9:6-14.

81. Bandura A. Social foundations of thought and action: a social cognitive theory. Upper SaddleRiver: Prentice Hall; 1986.

82. Hobfoll SE. Conservation of resources theory: its implication for stress, health, and resilience. In: Folkman S, editor. The Oxford handbook of stress, health, and coping. New York: Oxford University Press; 2011. p. 127-47.

83. Maisto SA, Carey KB, Bradizza CM. Social learning theory. In: Leonard KE, Blane HT, editors. Psychological theories of drinking and alcoholism. 2nd ed. New York: Guilford Press; 1999. p. 10663.

84. Ouimette P, Coolhart D, Funderburk J, Wade M, Brown PJ. Precipitants of first substance use in recenty abstinent substance use disorder patients with PTSD. Addict Behav. 2007;32:1719 27.

85. Walsh K, Blaustein M, Knight WG, Spinazzola J, van der Kolk BA. Resiliency factors in the relation between childhood sexual abuse and adulthood sexual assault in college-age women. J Child Sex Abus. 2007;16:1-17.

86. Annis HM, Graham JM. Situational Confidence Questionnaire (SCQ-39) user's guide. Toronto: Alcoholism and Drug Addiction Research Foundation; 1988.

87. Goldman MS, Brown SA, Christiansen BA, Smith GT. Alcoholism, etiology, and memory: broadening the scope of alcohol expectancy research. Psychol Bull. 1991;110:137-46.

88. Goldman MS, Del Boca FK, Darkes J. Alcohol expectancy theory: the application of cognitive neuroscience. In: Blane H, Leonard $\mathrm{K}$, editors. Psychological theories drinking and alcoholism. New York: Guilford Press; 1999. p. 203-46.

89. Ouimette PC, Ahrens C, Moos RH, Finney JW. During treatment changes in substance abuse patients with posttraumatic stress disorder: the influence of specific interventions and program environments. J Subst Abus Treat. 1998;15:555-64.

90. Simpson TL. Childhood sexual abuse, PTSD, and the functional roles of alcohol use among women drinkers. Subst Use Misuse. 2003;38:249-70.

91. Norman SB, Inaba RK, Smith TL, Brown SA. Development of the PTSD-Alcohol Expectancy Questionnaire. Addict Behav. 2008;33:841-7. 
92. Vik PW, Islam-Zwart KA, Ruge LN. Application of the PTSDalcohol expectancy questionnaire (P-AEQ) to sexually assaulted women. Addict Res Theory. 2008;16:585-94.

93. Cohn A, Hagman BT, Moore K, Mitchell J, Ehlke S. Does negative affect mediate the relationship between daily PTSD symptoms and daily alcohol involvement in female rape victims? Evidence from 14 days of interactive voice response assessment. Psychol Addict Behav. 2014;28(1):114-26.

94. Van Dam D, Ehring T, Vedel E, Emmelkamp P. Trauma-focused treatment for posttraumatic stress disorder combined with CBT for severe substance use disorder: a randomized controlled trial. BMC Psychiatry. 2013;13:172-85.

95. Hobfoll SE. Conservation of resources: a new attempt at conceptualizing stress. Am Psychol. 1989;44:513-24.

96. Khantzian EJ. The self-medication hypothesis revisited: the dually diagnosed patient. Prim Psychiatry. 2003;10:47-8.

97. Hruska B, Fallon W, Spoonster E, Sledjeski EM, Delahanty DL. Alcohol use disorder history moderates the relationship between avoidance coping and posttraumatic stress symptoms. Psychol Addict Behav. 2011;25:405-14.

98. Grasson DJ, Cohen LH, Moser JS, Hajcak G, Foa EB, Simons RF. Seeing the silver lining: potential benefits of trauma exposure in college students. Anxiety Stress Coping. 2012;25:117-36.

99. Filipas HH, Ullman SE. Child sexual abuse, coping responses, self-blame, posttraumatic stress disorder, and adult sexual revictimization. J Interpersonal Violence. 2006;21:652-72.

100. O'Hare T, Shen C, Sherrer M. High-risk behaviors and drinking-tocope as mediators of lifetime abuse and PTSD symptoms in clients with severe mental illness. J Trauma Stress. 2010;23(2):255-63.

101. Yeater EA, Austin JL, Green MJ, Smith JE. Coping mediates the relationship between posttraumatic stress disorder (PTSD) symptoms and alcohol use in homeless, ethnically diverse women: a preliminary study. Psychol Trauma Theory Res Pract Policy. 2010;2:307-10

102. Corbin WR, Bernat JA, Calhoun KS, McNair LD, Seals KL. The role of alcohol expectancies and alcohol consumption among sexually victimized and non-victimized college women. J Interpersonal Violence. 2001;16:297-311.

103. Read JP, Griffin MJ, Wardell JD, Ouimette P. Prospective Associations among Positive and Negative Coping Strategies, PTSD Symptoms and Alcohol Consequences in TraumaExposed College Students. Psychol Addict Behav. in press.

104. Brief DJ, Rubin A, Enggaser JL, Roy M, Keane TM. Web-based intervention for returning veterans with symptoms of posttraumatic stress disorder and risky alcohol use. J Contemp Psychother. 2011:41:237-46.

105. Gross JJ. The emerging field of emotion regulation: an integrative review. Rev Gen Psychol. 1998;2:271-99.

106. Weiss NH, Tull MT, Anestis MD, Gratz KL. The relative and unique contributions of emotion dysregulation and impulsivity to posttraumatic stress disorder among substance dependent inpatients. Drug Alcohol Depend. 2013;128:45-51.

107. Weiss NH, Tull MT, Viana AG, Anestis MD, Gratz KL. Impulsive behaviors as an emotion regulation strategy: examining associations between PTSD, emotion dysregulation, and impulsive behaviors among substance dependent inpatients. Journal of Anxiety Disorders. 2012;26:453-8.
108. McDermott MJ, Tull MT, Gratz KL, Daughters SB, Lejuez CW. The role of anxiety sensitivity and difficulties in emotion regulation in posttraumatic stress disorder among crack/cocaine dependent patients in residential substance abuse treatment. J Anxiety Disord. 2009;23:591-9.

109. Bornovalova MA, Ouimette P, Crawford AV, Levy R. Testing gender effects on the mechanisms explaining the association between post-traumatic stress symptoms and substance use frequency. Addict Behav. 2009;34(8):685-92.

110. Vujanovic AA, Bonn-Miller MO, Marlatt GA. Posttraumatic stress and alcohol use coping motives among a trauma-exposed community sample: the mediating role of non-judgmental acceptance. Addict Behav. 2011;36(7):707-12.

111. Berking M, Wupperman P, Reichardt A, Pejic T, Dippel A, Znoj H. Emotion-regulation skills as a treatment target in psychotherapy. Behav Res Ther. 2008;46:1230-7.

112. Gratz KL, Roemer L. Multidimensional assessment of emotion regulation and dysregulation: development, factor structure, and initial validation of the difficulties in emotion regulation scale. $\mathrm{J}$ Psychopathol Behav Assess. 2004;26(1):41-54.

113. Ray AE, Turrisi R, Abar B, Peters KE. The utility of predicting protective drinking behaviors and reducing alcohol-related consequences among college students. Addict Behav. 2009;34:911-7.

114. Barnett NP, Murphy JG, Colby SM, Monti PM. Efficacy of counselor vs. computer-delivered intervention with mandated college students. Addict Behav. 2007;32:2529-48.

115. Pearson MR. Use of alcohol protective behavioral strategies among college students: a critical review. Clin Psychol Rev. 2013;33:1025-40.

116. Johnson NL, Johnson DM. Factors influencing the relationship between sexual trauma and risky sexual behavior in college students. J Interpersonal Violence. 2013;28:2315-31.

117. LaBrie JW, Kenney SR, Lac A, Garcia JA, Ferraiolo P. Mental and social health impacts the use of protective behavioral strategies in reducing risky drinking and alcohol consequences. J Coll Stud Dev. 2009;50:35-49.

118. LaBrie JW, Kenney SR, Lac A. The use of protective behavioral strategies is related to reduced risk in heavy drinking college students with poorer mental and physical health. J Drug Educ. 2010;40:361-78.

119. Ozer EJ, Best SR, Lipsey TL, Weiss DS. Predictors of posttraumatic stress disorder and symptoms in adults: a meta-analysis. Psychol Bull. 2003;129:52-73.

120. King DW, Taft C, King LA, Hammond C, Stone ER. Directionality of the association between social support and posttraumatic stress disorder: a longitudinal investigation1. J Appl Soc Psychol. 2006;36(12):2980-92.

121. Moyers TB, Martin T, Houck JM, Christopher PJ, Tonigan JS. From in-session behaviors to drinking outcomes: a causal chain for motivational interviewing. J Consult Clin Psychol. 2009;77: 1113-24

122. Borsari B, Apodaca TR, Jackson KM, Magill M, Mastroleo N, Barnett NP, Carey KB. In-session processes of brief motivational interventions in two trials with mandated college students. J Consult Clin Psychol. (in press). 